\title{
El consumo en época de cuarentena, la modificación del comportamiento del consumidor en tiempos de COVD-19
}

Consumption in times of quarantine, modification of consumer behavior in times of COVD-19

Héctor Oswaldo Aguilar Cajas. ${ }^{1}$, Ana Lucía Rivera Abarca. ${ }^{2}$ \& Heidy Elizabeth Vergara Zurita. ${ }^{3}$

DOI: https://doi.org/10.33262/visionariodigital.v5i3.1777

\begin{abstract}
Introduction. The arrival of the pandemic to the new era, generated a total change in the pace of life of the people, factors such as telework, virtual education and confinement, made that people do not have the need to go out without counting on the fact of the fear that generated the probability of contagion, based on all these factors, the purchases of many increased, anticipating a possible shortage of basic necessities. The increase in the use of credit cards or ATMs was generated as a form of protection in the manipulation of potential elements of transmission of the virus. The investigation works in a nonexperimental one, with which the data could be obtained for its analysis.
\end{abstract}

Keywords: COVID-19, consumer, consumption patterns, payment method.

\section{Resumen}

Introducción. La llegada de la pandemia a la nueva era, generó un cambio total en los ritmo de vida de la gente, factores como teletrabajo, educación virtual y confinamiento, hicieron que las personas no tengan necesidad de salir además sin contar con el hecho del

\footnotetext{
1 Escuela Superior Politécnica de Chimborazo, Carrera de Mercadotecnia, Chimborazo, haguilar@espoch.edu.ec, http://orcid.org/0000-0003-2594-2486

2 Escuela Superior Politécnica de Chimborazo, Carrera de Diseño Gráfico, Chimborazo, arivera@espoch.edu.ec, http://orcid.org/0000-0002-2112-6492

3 Escuela Superior Politécnica de Chimborazo, Carrera de Diseño Gráfico, Chimborazo, heidy.vergara@espoch.edu.ec, http://orcid.org/0000-0002-6573-2339
} 
temor que generaba la probabilidad del contagio, en base a todos estos factores las compras de muchos aumentaron previendo un posible desabastecimiento de productos de primera necesidad. El aumento en uso de tarjetas de crédito o cajero se generó como una forma de protección en la manipulación de elementos potenciales de transmisión del virus. La investigación trabaja en una no experimental, con la cual se pudo obtener los datos para su análisis.

Palabras claves: COVID-19, consumidor, patrones de consumo, forma de pago

\section{Introducción.}

Desde el 2020 que se dio la llegada del coronavirus a la vida cotidiana fue considerada como la gran primera pandemia del Nuevo Milenio, a nivel mundial el virus marcó un antes y un después en muchos aspectos de la vida de las personas (Sardi, Rozo, Mosquera, Dusso, \& Vega, 2020). Las implicaciones causadas por este micro organismo el cual en todas las áreas y sociedades ha desencadenado impactantes consecuencias macro, esto generó que se de un cambio de paradigmas en el comportamiento de las personas.

El Diccionario de la Real Academia Española (DRAE), establece varias acepciones de la palabra paradigma, aunque en estas líneas solo son realmente interesantes las dos siguientes: 1) "Ejemplo o ejemplar". 2) "Teoría o conjunto de teorías cuyo núcleo central se acepta sin cuestionar y que suministra la base y modelo para resolver problemas y avanzar en el cono- cimiento". (Real Academia Española, 2021)

\section{El consumo}

En el contexto de la sociedad moderna, solemos considerar el consumo como todo acto de compra y uso de los productos para satisfacer las necesi- dades del ser humano. En todo consumo hay una apropiación y una transfor- mación, tanto material como simbólica, y por ello los usos del consumo son reflexivos: al consumir, se modifican y agotan los objetos, pero al consumir también se modifican, trasforman y expresan los sujetos sociales. (Alonso, Rodrígue, \& Rojo, 2020)

\section{COVID-19: cronología de la actuación de la OMS}

La Comisión Municipal de Salud de Wuhan (provincia de

31 de diciembre de 2019

Hubei, China) notifica un conglomerado de casos de neumonía en la ciudad. Posteriormente se determina que están causados por un nuevo coronavirus. (Organización Mundial de la Salud, 2021)

La OMS establece el correspondiente Equipo de Apoyo a la

1 de enero de 2020 Gestión de Incidentes en los tres niveles de la Organización - la Sede, las sedes regionales y los países - y pone así a la Organización en estado de emergencia para abordar el brote. 
La OMS informa en las redes sociales de la existencia de un

4 de enero de 2020 conglomerado de casos de neumonía - sin fallecimientosen Wuhan (provincia de Hubei).

La OMS publica su primer parte sobre brotes epidémicos relativo al nuevo virus, una publicación técnica de referencia para la comunidad mundial de investigación y salud pública y los medios de comunicación. El parte contiene una

5 de enero de 2020 evaluación del riesgo y una serie de recomendaciones, así como la información proporcionada por China a la Organización sobre la situación de los pacientes y la respuesta de salud pública ante el conglomerado de casos de neumonía de Wuhan.

La OMS publica en línea un amplio conjunto de orientaciones técnicas con recomendaciones para todos los países sobre el modo de detectar casos, realizar pruebas de laboratorio y gestionar los posibles casos. Las orientaciones se basan en los conocimientos sobre el virus que existen en ese momento. Las orientaciones se remiten a los directores regionales de la OMS para emergencias a fin de que las

10 de enero de 2020

12 de enero de 2020

13 de enero de 2020

14 de enero de 2020

20-21 de enero 2020 distribuyan entre los representantes de la OMS en los países.

Tomando como base la experiencia con el SARS y el MERS, así como las vías de transmisión conocidas de los virus respiratorios, se publican orientaciones sobre la prevención y el control de infecciones destinadas a proteger a los profesionales sanitarios, en las que se recomienda adoptar precauciones contra la transmisión por gotículas y por contacto al atender a los pacientes, así como precauciones contra la transmisión aérea en las intervenciones asociadas a la generación de aerosoles.

China hace pública la secuencia genética del virus causante de la COVID-19.

Se confirma oficialmente un caso de COVID-19 en Tailandia, el primero registrado fuera de China.

La responsable técnica de la OMS para la respuesta señala en una conferencia de prensa que se ha producido una transmisión limitada del coronavirus entre seres humanos (en los 41 casos confirmados), fundamentalmente a través de familiares, y que existe el riesgo de un posible brote más amplio. La responsable técnica observa que una transmisión entre seres humanos no sería sorprendente habida cuenta de nuestra experiencia con los patógenos causantes del SARS, el MERS y otras enfermedades respiratorias.

Expertos de la oficina de la OMS en China y de la Oficina Regional para el Pacífico Occidental efectúan una breve visita sobre el terreno a Wuhan. 
La misión de la OMS a China emite una declaración en la

22 de enero de 2020 que se afirma que se ha demostrado la transmisión entre seres humanos en Wuhan, si bien se necesitan más investigaciones para comprender plenamente la magnitud de esta transmisión.

Tabla 1. Localidad

Fuente: (Organización Mundial de la Salud, 2020)

\section{EI COVID-19 en el Ecuador}

De acuerdo con Boletín de prensa del Ministerio de Salud Pública del Ecuador, el viernes 13 de marzo se produjo en Ecuador la primera persona fallecida a causa del coronavirus (COVID-19). En rueda de prensa, desde el ECU 911 de Guayaquil, explicó que el deceso corresponde al primer caso que se confirmó en el país. En base a la primera muerte dada por el COVID-19, desde el 17 de marzo de 2020 se decretó la restricción de movilidad y suspensión de trabajo particular, esta restricción tuvo como primera fecha tentativa final el 31 de marzo del mismo año. Además que se determinó un toque de queda en todo el territorio nacional desde las 14:00 hasta las 05:00. (El Universo, 2020)

"El fallecimiento sucedió este mediodía en la casa de salud donde estaba internada, desde el pasado 22 de febrero de 2020", expresó la ministra. Asimismo, informó de tres nuevos casos positivos de COVID-19 en territorio nacional. Detalló que dos de los últimos tres pacientes provienen de España y otro de Suecia. Además, precisó que, del total de los 23 casos, cinco están en Pichincha, ocho en Guayas y 10 en Los Ríos. "De total de casos, tres están ingresados en una casa de salud y se encuentran estables, en Guayas. Mientras que dos se hallan en estado crítico, en Pichincha”, especificó la ministra Andramuño. (Ministerio de Salud, 2020)

De acuerdo a datos del Banco Central del Ecuador el confinamiento generado por la pandemia hizo que los ciudadanos tengan una mayor confianza en el uso de los medios de pago electrónicos, generando esto un crecimiento del $35 \%$ en el número de transacciones por pagos interbancarios realizados por los clientes del sistema financiero entre mayo - septiembre 2020. (Círculo de Estudios Latinoamericanos, 2021) Hay que tener en cuenta que los meses en mención fueron los de mayor confinamiento por parte de las personas lo que hacía, que el uso de circulante físico como billetes sea menor. (Super Intendencia de Bancos, 2019)

"En relación con otros medios de pago electrónicos, en pandemia (marzo-agosto 2020) la ciudadanía redujo el uso de tarjetas de crédito tanto en montos como en operaciones, manteniéndose bajo los niveles de consumo del año anterior. Mientras que el uso de las tarjetas de débito se recuperó brevemente a los niveles alcanzados en el 2019. Por su parte, se observó que los comercios también vieron la necesidad de implementar puntos de venta electrónico (POS) para brindar mayor facilidad a sus clientes para el uso de medios electrónicos de pagos, principalmente aquellos que ahora permiten realizar compras por páginas web; en pandemia se incrementó 10,382 POS entre marzo -agosto 2020 en el Ecuador" (Banco Central del Ecuador, 2021) 
La declaratoria de emergencia conllevó un cambio muy grande en la rutina de las personas, al generarse restricciones de movilidad y horarios de atención, obligó a muchos a modificar sus patrones de consumo, circunstancias como el miedo, la limitada movilidad o el desabastecimiento de los productos influyó, en que el consumo de productos halla aumentado con relación a épocas anteriores. El consumidor ecuatoriano no se ha caracterizado por tener un alto uso de medio digitales de pago, la investigación demostró que al momento de efectivizar la compra, el tipo de pago dependía en gran medida de la localidad o residencia de cada uno de los consumidores.

\section{Metodología}

El estudio en mención es parte de una investigación macro, no experimental, correlacional, transversal, de campo, en la cual el principal objetivo fue determinar como fue afectado el modo de consumo en base a la cuarentena generada. El universo de estudio son las 3 regiones que comprenden al Ecuador de la cual se obtiene un total de 644 encuestas, para la realización de esta se trabajó con la participación de los estudiantes de la Carrera de Mercadotecnia de la Escuela Superior Politécnica de Chimborazo, lo cual en su mayoría son pertenecientes a la región Sierra.

\section{Resultados}

Dentro de los resultados cualitativos obtenidos en la investigación se tomó una muestra de 644 participantes de las 3 regiones del Ecuador, la muestra en mención fue dada en base al hecho de que la ESPOCH tiene estudiantes de las regiones en mención.

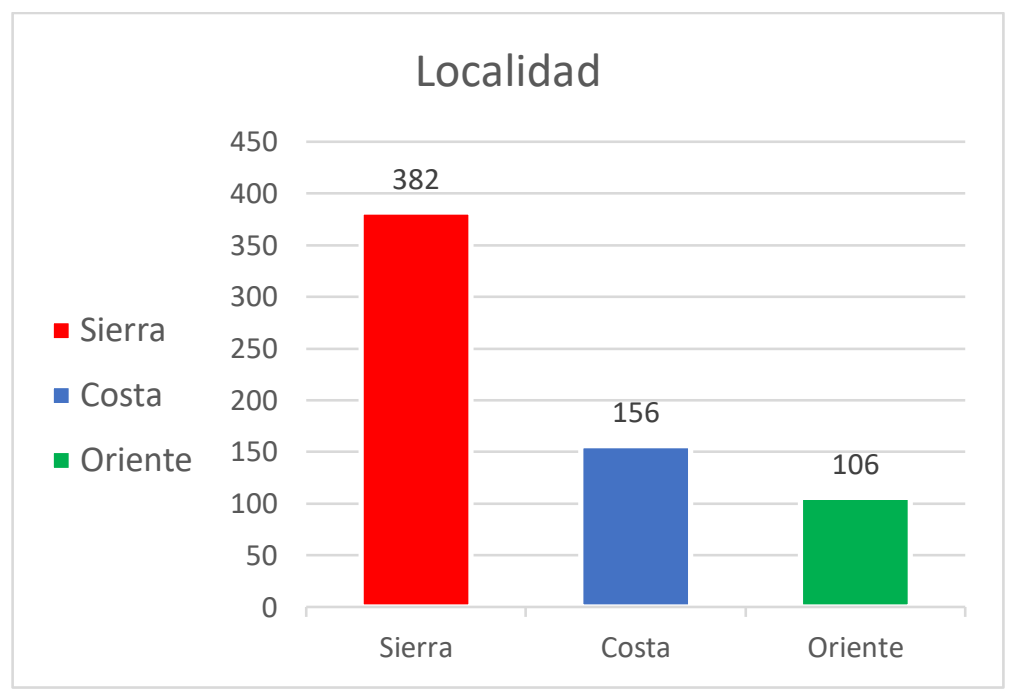

Gráfico 1. Localidad

Fuente: Elaboración propia.

\section{Interpretación}

La mayor cantidad de personas encuestadas fueron de la región sierra, esto debido a la ubicación de la ESPOCH y de que la mayor cantidad de estudiantes son de estas localidades. 
¿Considera usted que el consumo en la época de confinamiento aumentó, disminuyó o fue igual?

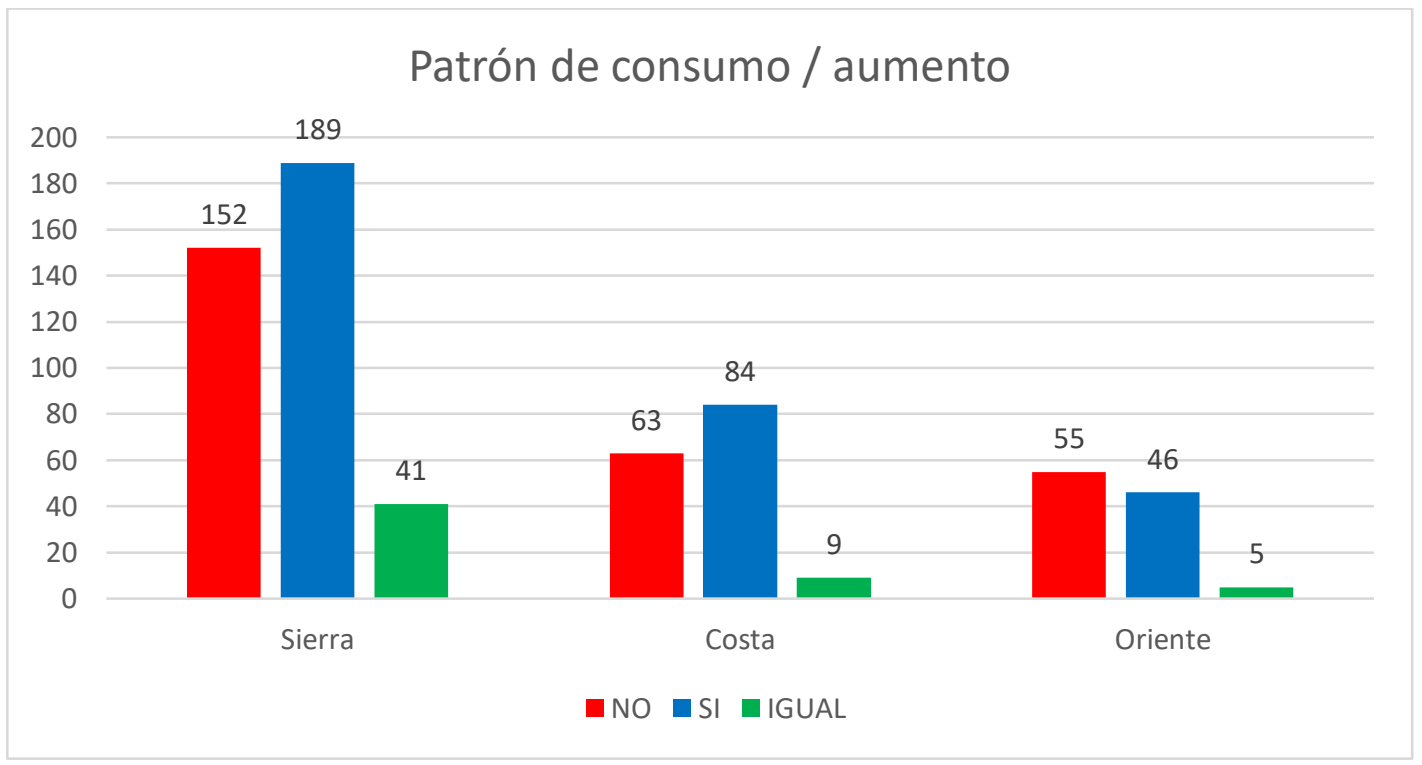

Gráfico 2. Patrón de consumo / aumento

Fuente: Elaboración propia.

\section{Interpretación}

A las personas se les preguntaba si consideran que el consumo aumentó o disminuyó y se pudo evidenciar que a nivel de la serranía y costa ecuatoriana este fue en aumento, esto se debió en gran medida al temor generado por el confinamiento de las personas y el temor de contagio que generaba.

¿La forma de pago preferida por usted es, efectivo o tarjeta?

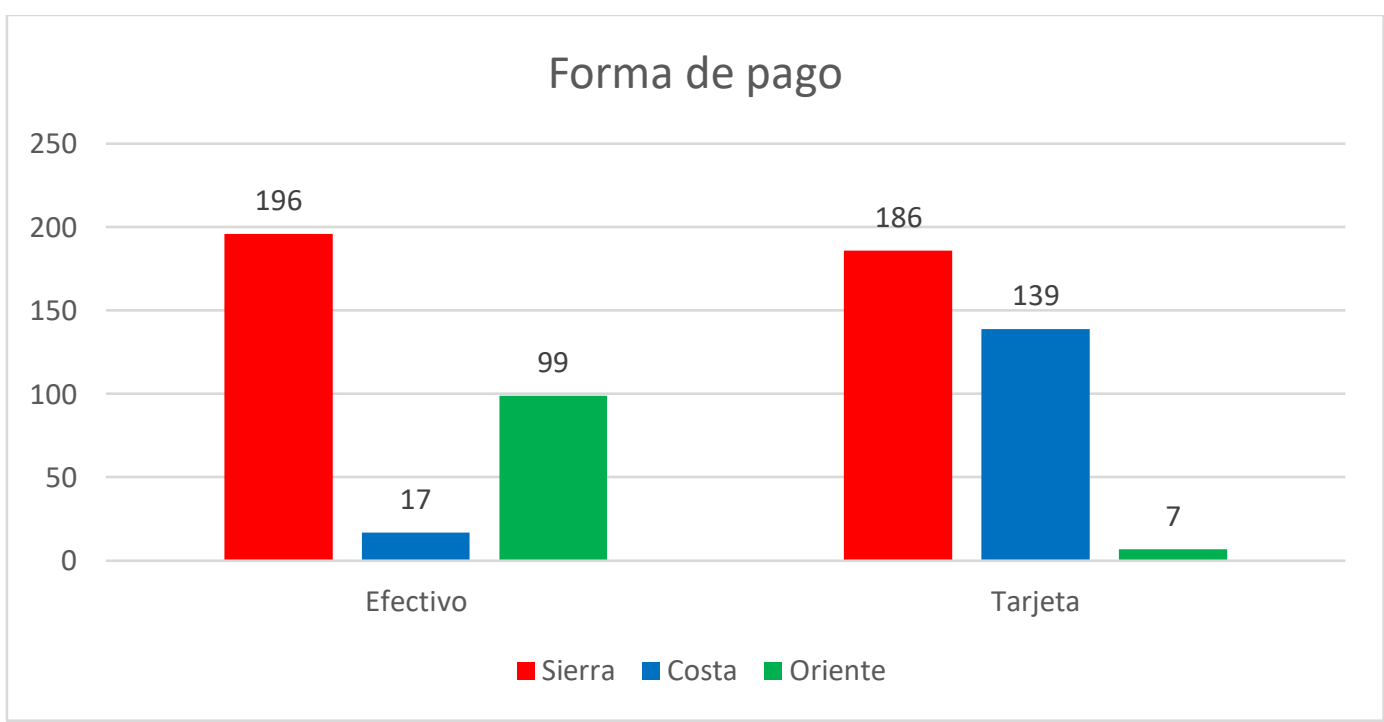

Gráfico 3. Forma de pago

Fuente: Elaboración propia. 


\section{Interpretación}

La localidad de procedencia de las personas evidencia claramente como la forma de pago influye, ya que en la sierra la tendencia es casi igual, esto determina que el consumidor utiliza tanto efectivo como tarjeta de forma casi igual. A diferencia de la costa, en la que el consumidor hace un mayor uso de la tarjeta como forma de pago. Pero a nivel del oriente ecuatoriano, las personas no hacen mayor uso de la tarjeta y sus compras son en efectivo.

\section{Conclusiones}

- La cuarentena generada por el COVID-19, trajo consigo cambios drásticos en la forma de vida de las personas, el teletrabajo y la educación virtual hizo que las personas tengan cada vez menos necesidad de salir de sus hogares, también teniendo en cuenta que el temor de contagio fue un factor influyente de mantenerse a salvo en las casas.

- Uno de los factores principales del aumento del consumo de las personas fue el temor a contagiarse en lugares publico, lo que generaba que hicieran mayores compras, en lapsos de tiempo más largo para de esta forma no tener que salir tantas veces a los supermercados.

- Se pudo evidenciar como la localidad de las personas influía mucho al momento del uso diferentes medios de consumo, ya que en la región sierra y costa el uso estaba en aumento, mientras que en la región oriental las personas no confiaban en medios alternativos de compra.

\section{Referencias bibliográficas}

Alonso, L. E., Rodrígue, C. F., \& Rojo, R. I. (2020). Estudios sociales sobre el consumo. Centro de Investigaciones Sociológicas (1. ${ }^{\mathrm{a}}$ ed.). Centro de Investigaciones Sociológicas.

Banco Central del Ecuador. (2021). EVOLUCIÓN DE LOS MEDIOS DE PAGO DEL ECUADOR EN EL CONTEXTO DE PANDEMIA COVID -19. Recuperado de https://contenido.bce.fin.ec/documentos/Administracion/snp-estadistica-2.pdf

Círculo de Estudios Latinoamericanos. (2021). Aumenta consumo con tarjetas de débito y baja el uso de las de crédito en Ecuador. Recuperado de https://www.cesla.com/detalle-noticias-de-ecuador.php?Id=20917

El Universo. (2020). Las medidas que toma Ecuador, en emergencia sanitaria por coronavirus: cuarentena de pasajeros internacionales, suspensión de clases y eventos masivos. Recuperado de https://www.eluniverso.com/noticias/2020/03/12/nota/7778376/coronavirusecuador-viaje-restriccion-vuelos-pasajeros-aeropuertos

Ministerio de Salud. (2020). Ministra de Salud confirma muerte de paciente por COVID19. Recuperado de https://www.salud.gob.ec/ministra-de-salud-confirma-muerte- 
de-paciente-por-covid-19/

Organización Mundial de la Salud. (2020). COVID-19: cronología de la actuación de la OMS. Recuperado de https://www.who.int/es/news/item/27-04-2020-who-timeline--covid-19

Organización Mundial de la Salud. (2021). Cronología de la respuesta de la OMS a la COVID-19. Recuperado de https://www.who.int/es/news/item/29-06-2020covidtimeline

Real Academia Española. (2021). Paradigma. Recuperado de https://dle.rae.es/paradigma

Sardi, X. C., Rozo, D. C., Mosquera, D. P. Q., Dusso, J. J. F., \& Vega, R. S. (2020). Ensayos sobre la pandemia. Recuperado de https://repository.icesi.edu.co/biblioteca_digital/bitstream/10906/86919/6/londono _ensayos_pandemia_2020.pdf

Super Intendencia de Bancos. (2019). SISTEMA DE BANCOS PRIVADOS REPORTE COMPORTAMIENTO CREDITICIO SECTORIAL Período: Marzo 2018 - Marzo 2019. 


\section{PARA CITAR EL ARTÍCULO INDEXADO.}

Aguilar Cajas, H. O., Rivera Abarca, A. L., \& Vergara Zurita, H. E. (2021). El consumo en época de cuarentena, la modificación del comportamiento del consumidor en tiempos de COVD-19. Visionario Digital, 5(3), 102-110. https://doi.org/10.33262/visionariodigital.v5i3.1777

\section{Ciencia \\ Digital \\ Editorial}

El artículo que se publica es de exclusiva responsabilidad de los autores y no necesariamente reflejan el pensamiento de la Revista Visionario Digital.

El artículo queda en propiedad de la revista y, por tanto, su publicación parcial y/o total en otro medio tiene que ser autorizado por el director de la Revista Visionario Digital.
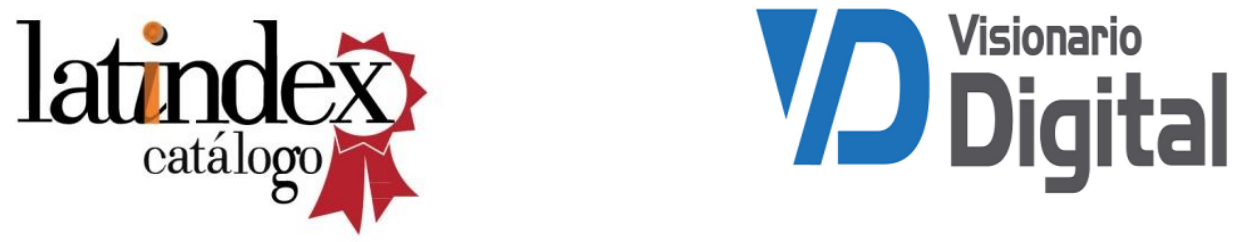